Polymer Journal, Vol. 38, No. 7, pp. 669-677 (2006)

(C) 2006 The Society of Polymer Science, Japan

\title{
Fast and Large Stretching Bis(trifluoromethylsulfonyl)imide (TFSI)-doped Polypyrrole Actuators and Their Applications to Small Devices
}

\author{
Tetsuji ZAMA,${ }^{1,2, \dagger}$ Noboru TANAKA, ${ }^{1}$ Wataru TAKAShImA, ${ }^{2}$ and Keiichi KANETO ${ }^{2}$ \\ ${ }^{1}$ EAMEX Co., 3-9-30 Tarumi-cho, Suita 564-0062, Japan \\ ${ }^{2}$ Graduate School of Life Science and Systems Engineering, Kyushu Institute of Technology, \\ 2-4 Hibikino, Wakamatsu-ku, Kitakyushu 808-0196, Japan
}

(Received November 2, 2005; Accepted March 1, 2006; Published May 29, 2006)

\begin{abstract}
Bis(trifluoromethylsulfonyl)imide (TFSI)-doped polypyrrole (PPy) films were prepared electrochemically from an aromatic ester solution of tetra- $n$-butylammonium bis(trifluoromethylsulfonyl)imide (TBATFSI) at $-10^{\circ} \mathrm{C}$ on various metal and carbon electrodes. TFSI-doped PPy actuators exhibited more than $20 \%$ electrochemical strains with fast response rate $\left(<13.8 \% \mathrm{~s}^{-1}\right)$ when driven electrochemically in a propylene carbonate (PC)/water mixed solution of LiTFSI. The maximum electrochemical strain of TFSI-doped PPy actuators was 35.2\%, which was equivalent to strains of mammalian skeletal muscles. The fast and large electrochemical strain was ascribed to smooth insertion and release of large dopant anions (TFSI), resulting from slight disentanglement and swell of TFSI-doped PPy films in PC/water solution of LiTFSI. Due to the moderate mechanical strength of TFSI-doped PPy films, TFSI-doped PPy should be supported by compliant metal electrodes such as metal micro-coils. Encapsulated artificial muscle fibres, comprising a TFSI-doped PPy Au coil composite actuator, a TFSI-doped PPy tube as the counter electrode, a separator, and a PC/water solution of LiTFSI as the driving electrolyte, exhibited a smooth electrochemical stretching and most suitable for small applications. [doi:10.1295/polymj.PJ2005165]

KEY WORDS Conducting Polymer Actuator / Artificial Muscle / Polypyrrole / Bis(trifluoromethylsulfonyl)imide / Artificial Muscle Fibre /
\end{abstract}

Conducting polymers (CPs) have been expected as artificial muscles for years due mainly to their large electrochemical stress (3-5 MPa) ${ }^{1-5} 10$ times as large as that $(0.35 \mathrm{MPa})^{6}$ of mammalian skeletal muscles, but the electrochemical strain of $\mathrm{CP}$ actuators has just reached the same level of muscles $(20-40 \%) \cdot{ }^{7,8}$ Since the dawn of CP actuators, linear displacement of most $\mathrm{CP}$ actuators has been hardly seen because of the small electrochemical strain (1-3\%), and therefore bimorph devices have been fabricated by using CPs such as polypyrrole (PPy) and polyaniline., ${ }^{3,9}$ The latest bimorph devices showed a fast bending motion at $<50 \mathrm{~Hz}$ in electrolytic solution and in air. ${ }^{10}$ To our knowledge, however, most applications by using CP actuators require the linear actuation rather than the bending motion, and thus we have been focussing mainly on liner actuators.

Amongst $\mathrm{CP}$ actuators investigated, we found two totally different PPy actuators. Electrochemically synthesized PPy films doped with bis(trifluoromethylsulfonyl)imide $\left[\left(\mathrm{CF}_{3} \mathrm{SO}_{2}\right)_{2} \mathrm{~N}^{-}\right.$, TFSI] anion exhibited more than $20 \%$ strain almost equivalent to that of natural muscles, and thus suitable for artificial muscle devices requiring large displacements. ${ }^{8}$ TFSI-doped PPy actuators used to actuate very slowly, and the maximum electrochemical strain $(26.5 \%)$ was firstly re- ported, when driven in an aqueous LiTFSI solution, and the slow actuation was considered to be a natural result due to large TFSI anions (ionic radius: 0.325 $\mathrm{nm})^{11}$ as the dopant. The maximum electrochemical strain increased with larger $\mathrm{Li}\left(\mathrm{C}_{\mathrm{n}} \mathrm{F}_{2 \mathrm{n}+1} \mathrm{SO}_{2}\right)_{2} \mathrm{~N}(\mathrm{n}=$ 1-4), which was employed as the electrolyte both for the electropolymerization and driving the PPy actuators obtained. ${ }^{12}$ Recently, TFSI-doped PPy actuators exhibited much faster actuation with the peak response rate of $13.8 \% \mathrm{~s}^{-1}$ by using a propylene carbonate (PC)/water mixed solution of LiTFSI as the driving electrolyte. ${ }^{13,14}$ The massive improvement in the response rate was attributable to disentanglement of TFSI-doped PPy swollen in PC/water where high ionic conductivity was maintained.

On the other hand, PPy films doped with trifluoromethanesulfonate $\left(\mathrm{CF}_{3} \mathrm{SO}_{3}{ }^{-}\right.$, triflate) anion showed $12.8 \%$ of the maximum electrochemical strain and $49 \mathrm{MPa}$ of the maximum electrochemical stress. ${ }^{15-17}$ The large electrochemical stress was 140-fold that of mammalian skeletal muscles, and therefore the triflate-doped PPy was classed as a powerful CP actuator. As the triflate-doped PPy actuator was invented one-year prior to the TFSI-doped PPy, most devices have been fabricated by using triflate-doped PPy thus far. Another reason why TFSI-doped PPy has

${ }^{\dagger}$ To whom correspondence should be addressed (Tel: +81-6-6368-8434, Fax: +81-6-6368-8435, E-mail: t.zama@eamex.co.jp). 
not been used as artificial muscle devices was that TFSI-doped PPy exhibited moderate electrochemical stress and mechanical strength such that not suitable for large devices. The TFSI-doped PPy should be used as small devices such as micro electro-mechanical systems (MEMS) applications. In this paper, the improvement in actuator performance of TFSI-doped PPy and some applications of TFSI-doped PPy are described.

\section{EXPERIMENTAL}

\section{Materials}

Pyrrole (Wako Pure Chemical Industries, Ltd.), methyl benzoate (Wako), dimethyl phthalate (Wako), 4-methyl-1,3-dioxolan-2-one (propylene carbonate, PC) (Wako), lithium bis(trifluoromethylsulfonyl)imide (LiTFSI) (Morita Chemical Industries Co., Ltd.), tetra- $n$-butylammonium bis(trifluoromethylsulfonyl)imide (TBATFSI) (Tomiyama Pure Chemical Industries, Ltd.), 1-ethyl-3-methylimidazolium bis(trifluoromethylsulfonyl)imide (EMI-TFSI) (Kishida Chemical Co., Ltd.), 1,1-ethylmethylpyrrolidium bis(trifluoromethylsulfonyl)imide (EMP-TFSI) (Kishida), 1-butylpyridinium bis(trifluoromethylsulfonyl)imide (BP-TFSI) (Kishida), and trimethylpropylammonium bis(trifluoromethylsulfonyl)imide (TMPA-TFSI) (Kishida) were purchased and used without further purification.

Platinum/iridium (Ir: 20\%) and gold micro-coils (diameter of the coil: $0.25 \mathrm{~mm}$, diameter of the metal wire: $25 \mu \mathrm{m}$, the pitch: $50 \mu \mathrm{m}$ ) were obtained from Nippon Cable System Inc.

\section{Electrochemical Polymerization of Pyrrole}

Preparation of free-standing TFSI-doped PPy films was mainly performed in a one compartment threeelectrode cell by a standard constant-potential electropolymerization of pyrrole $\left(0.25 \mathrm{~mol} \mathrm{dm}^{-3}\right)$ from aromatic ester solution of TBATFSI $\left(0.2 \mathrm{~mol} \mathrm{dm}^{-3}\right)$ at $+1.4 \mathrm{~V}$ vs. $\mathrm{Ag} / \mathrm{AgCl}$ on glassy carbon (GC), $\mathrm{Pt}, \mathrm{Ti}$, $\mathrm{Ni}$, and ITO electrode at $-10^{\circ} \mathrm{C}$, driven by a Hokuto Denko HA-151 potentiostat-galvanostat. Methyl benzoate (MB), dimethyl phthalate (MP), and MB/MP $(1 / 5)$ mixed solvent were used for the electropolymerization. A constant-current method was also conducted by using a two-electrode cell at $0.1 \mathrm{~mA} \mathrm{~cm}^{-2}$. PPy films obtained were immersed in acetone, peeled off the electrode and air-dried.

Preparation of TFSI-doped PPy-Au coil composites was carried out by using an $\mathrm{Au}$ coil as the working electrode by potential-control method at $+1.2 \mathrm{~V} v s$. $\mathrm{Ag} / \mathrm{AgCl}$ at $-10^{\circ} \mathrm{C}^{18}$ Tubular PPy fibres with $\mathrm{Au}$ micro-coil was rinsed with acetone and air-dried. TFSI-doped PPy tubes were prepared by potential- constant electropolymerization at $+1.4 \mathrm{~V}$ vs. $\mathrm{Ag} /$ $\mathrm{AgCl}$ on $\mathrm{Pt}$ and $\mathrm{Ni}$ wires as the working electrode whose diameters were $0.8 \mathrm{~mm}$ and $1.0 \mathrm{~mm}$, respectively. The metal wire was pulled out of the PPy coated metal wire when immersed in acetone. Note that PPy doped with TFSI swelled considerably in acetone.

Measurements of Fundamental Properties of PPy Films

The electric conductivity of PPy films was measured by using a standard 4-probe technique with a Loresta-GP (Mitsubishi Chemical). Observation of surface morphology of PPy films, PPy-Au coil composites, and PPy tubes was carried out with a Hitachi S-3000N scanning electron microscope (SEM).

\section{Electrochemical Stretching of PPy Actuators}

Electrochemomechanical deformation (ECMD) of PPy actuators was measured by the use of a one-compartment three-electrode cell with a pin hole at the bottom through which a $\mathrm{W}$ wire passed to suspend a load (0.1 MPa for measuring the maximum strain) as described in previous papers. ${ }^{15,17}$ PPy films were cut into a $10-\mathrm{mm} \times 2-\mathrm{mm}$ strip and set in the three-electrode cell, and the PPy strip was operated by applying potential between $-0.9 \mathrm{~V}$ and $+0.7 \mathrm{~V} v s$. $\mathrm{Ag} / \mathrm{Ag}^{+}$ at $2 \mathrm{mV} \mathrm{s}^{-1}$ in PC/water (40/60) mixed solution of LiTFSI by the use of a Princeton Applied Research 263A potentio-galvanostat, when the maximum electrochemical strain was measured. The expansioncontraction ratio (the electrochemical strain) of the PPy strip was monitored by using a KEYENCE LE-4000 laser displacement meter. The definition of electrochemical strain (\%) of PPy actuators was $\left(\Delta \mathrm{l} / \mathrm{l}_{0}\right) \times 100$, where $\Delta \mathrm{l}$ and $\mathrm{l}_{0}$ were change in length and the original length of the PPy strip, respectively. Measurement of electrochemical stress of PPy actuators was performed with a procedure described elsewhere ${ }^{15,17}$ by applying potential ranges mentioned above at $10 \mathrm{mV} \mathrm{s}^{-1}$.

Electrochemical contraction and elongation was performed by applying a constant potential of $-0.7 \mathrm{~V}$ and $+0.7 \mathrm{~V} v s . \mathrm{Ag} / \mathrm{Ag}^{+}$, respectively, for $100 \mathrm{~s}$ except for the second elongation (30 s) at room temperature. The electrochemical contraction ratios for the third contraction were usually shown in the following tables. Note that the third contraction was conducted after the first contraction (100s) and elongation (100 s), and the second contraction (100 s) and elongation $(30 \mathrm{~s})$.

Repeated electrochemical stretching was performed by using a Hokuto Denko HA-151 potentio-galvanostat and a Wave Factory WF1946 multifunction synthesizer in PC/water mixed solution of LiTFSI at -0.7 $\mathrm{V}$ and $+0.7 \mathrm{~V} v s . \mathrm{Ag} / \mathrm{Ag}^{+}$at $0.05 \mathrm{~Hz}$ (square pulse). 
Table I. Electrochemical strains and physical properties of TFSI-doped PPy actuators prepared electrochemically from a dimethyl phthalate solution of TBATFSI on various electrodes at $-10^{\circ} \mathrm{C}$

\begin{tabular}{|c|c|c|c|c|c|c|c|c|c|c|c|}
\hline Electrode & $\mathrm{Pt}$ & $\mathrm{Pt}$ & $\mathrm{Ti}$ & $\mathrm{Ti}$ & $\mathrm{Ni}$ & $\mathrm{Ni}$ & GC & $\mathrm{GC}$ & ITO & ITO & $\mathrm{Au}$ \\
\hline Potential/V vs. $\mathrm{Ag} / \mathrm{AgCl}$ & +1.4 & +2.0 & +1.4 & +2.0 & +1.4 & +2.0 & +1.4 & +2.0 & +1.4 & +2.0 & $\left(0.1 \mathrm{~mA} \mathrm{~cm}^{-2}\right)$ \\
\hline Polymerization time/h & 23.5 & 9 & 9 & 9 & 24 & 9 & 55 & 31 & 23 & 23 & 8 \\
\hline Conductivity $/ \mathrm{S} \mathrm{cm}^{-1}$ & 195 & 172 & 36 & 53 & 197 & 141 & 252 & 196 & 44 & 50 & 58 \\
\hline Thickness/ $\mu \mathrm{m}$ & 22 & 11 & 63 & 32 & 16 & 17 & 25 & 42 & 53 & 53 & 43 \\
\hline $\begin{array}{l}\text { Maximum electrochemical } \\
\text { strain/\% }\end{array}$ & 25.5 & 21.5 & 23.6 & 20.2 & 17.4 & 16.6 & 31.1 & 29.7 & 11.5 & 8.5 & 27.6 \\
\hline Contraction ratio/\% & & & & & & & & & & & \\
\hline for $2 \mathrm{~s}$ & 8.1 & 15.4 & 16.8 & 15.7 & 12.2 & 10.8 & 11.5 & 13.9 & 5.5 & 5.0 & 14.7 \\
\hline $5 \mathrm{~s}$ & 13.1 & 19.7 & 22.0 & 21.1 & 15.9 & 14.0 & 17.4 & 21.3 & 9.1 & 7.7 & 19.7 \\
\hline $10 \mathrm{~s}$ & 16.0 & 21.7 & 23.9 & 23.6 & 17.4 & 15.5 & 20.2 & 25.2 & 10.9 & 8.8 & 21.6 \\
\hline $100 \mathrm{~s}$ & 20.9 & 25.1 & 26.6 & 27.8 & 20.0 & 18.2 & 24.7 & 30.6 & 13.8 & 10.8 & 24.5 \\
\hline Peak response rate $/ \% \mathrm{~s}^{-1}$ & & & 12.8 & 13.8 & & & & & & & 12.2 \\
\hline
\end{tabular}

\section{RESULTS AND DISCUSSION}

\section{Fast ECMD of TFSI-doped PPy Actuators Prepared on Various Electrodes}

Table I shows electrochemical strains and some physical properties of TFSI-doped PPy actuators prepared electrochemically from a dimethyl phthalate (MP) solution of TBATFSI on various electrodes. The order of the maximum electrochemical strain of TFSI-doped PPy actuators was as follows;

$$
\mathrm{GC}>\mathrm{Pt}>\mathrm{Ti}>\mathrm{Ni}>\mathrm{ITO} \text {. }
$$

Indium tin oxide (ITO) electrode gave less entangled PPy chains exhibiting a large elongation and a small contraction, that is, the PPy actuator gave up the load (ca. 0.1 MPa) when electrochemical stretching was conducted. Ni electrode often gave a loosen PPy chains showing small strains, and the film obtained was able to peel off the electrode quite easily. This was one of the reasons why a $\mathrm{Ni}$ wire was chosen as the working electrode in order to prepare TFSI-doped PPy tubes. On the contrary, glassy carbon (GC) electrode gave dense TFSI-doped PPy films, which did not swell very much in acetone but shrank considerably on drying. ${ }^{14}$ TFSI-doped PPy actuators prepared on GC showed the largest electrochemical strain because highly shrunk PPy actuators might have a great room for elongation.

MP is inclined to give softer and less dense TFSIdoped PPy films, exhibiting fast electrochemical stretching. To our knowledge, the peak response rate of $13.8 \% \mathrm{~s}^{-1}$ was the fastest in $\mathrm{CP}$ actuators, at least in free-standing $\mathrm{CP}$ films without any compliant electrode or metal backing. The condition of electrochemical polymerization was not appropriate, however, because the electrolytic solution comprising MP (m.p.: $+2{ }^{\circ} \mathrm{C}$ ) was viscous and the ionic conductivity appeared to be low. When the electropolymerization was performed at room temperature, the electrolytic solution became less viscous and the ionic conductivity increased but the TFSI-doped PPy films obtained exhibited poor actuator performance. Moreover, potential constant electropolymerization at $+1.4 \mathrm{~V} v s$. $\mathrm{Ag} / \mathrm{AgCl}$ took long time and higher applied potential of $+2.0 \mathrm{~V}$ presumably damaged PPy showing lower electric conductivity of the films obtained and poorer actuator performance.

\section{Large ECMD of TFSI-doped PPy Actuators Prepared from $M B / M P$ Solution}

Table II shows electrochemical strains and some physical properties of TFSI-doped PPy actuators prepared electrochemically from a methyl benzoate/ dimethyl phthalate (MB/MP) (1/5) mixed solution of TBATFSI on GC, Ti, and Pt. The viscosity of the electrolytic solution was lower than that of MP solution of TBATFSI mentioned above. The maximum strains of TFSI-doped PPy actuators prepared electrochemically on GC were around 30\%, almost equal to those prepared from MP solution shown in Table I. Methyl benzoate (MB) was usually employed to prepare triflate-doped PPy films that were compact and smooth, and the interaction between PPy chains appeared to be very strong. MB/MP (1/5) mixed solution of TBATFSI gave soft and less dense PPy films exhibiting fast and large ECMD. Viscous MP solution of TBATFSI gave soft and less dense TFSI-doped PPy films where the interaction between PPy chains might be weak, whereas MB/MP solution also gave soft and less dense TFSI-doped PPy films that still kept strong interaction between PPy chains, thanks to the addition of MB. Therefore, MB/MP solution of TBATFSI gave TFSI-doped PPy films exhibiting fast and large electrochemical strain. GC electrodes gave highly entangled PPy chains even though MP was used as solvent, and thus the maximum electrochemical strains of TFSI-doped PPy actuators prepared on GC by using 
Table II. Electrochemical strains and physical properties of TFSI-doped PPy actuators prepared from $\mathrm{MB} / \mathrm{MP}(1 / 5)$ mixed solution of TBATFSI at $-10^{\circ} \mathrm{C}$

\begin{tabular}{|c|c|c|c|c|c|c|c|c|c|c|}
\hline Electrode & GC & GC & GC & GC & $\mathrm{GC}$ & $\mathrm{Ti}$ & $\mathrm{Ti}$ & \multicolumn{3}{|c|}{$\mathrm{Pt}$} \\
\hline Potential/V vs. $\mathrm{Ag} / \mathrm{AgCl}$ & +1.2 & +1.4 & +1.6 & +2.0 & $\left(0.1 \mathrm{mAcm}^{-2}\right)$ & +1.4 & +2.0 & +1.4 & +2.0 & $\left(0.1 \mathrm{~mA} \mathrm{~cm}^{-2}\right)$ \\
\hline Polymerization time $/ \mathrm{h}$ & 8 & 6 & 9 & 4 & 24 & 9 & 7 & 9 & 9 & 8 \\
\hline Conductivity $/ \mathrm{S} \mathrm{cm}^{-1}$ & 87 & 48 & 153 & 48 & 155 & 180 & 176 & 54 & 84 & 53 \\
\hline Thickness/ $/ \mu \mathrm{m}$ & 63 & 120 & 39 & 80 & 64 & 21 & 17 & 60 & 58 & 56 \\
\hline $\begin{array}{l}\text { Maximum electrochemical } \\
\text { strain } / \%\end{array}$ & 31.7 & 33.5 & 29.6 & 27.1 & 33.3 & 27.5 & 23.5 & 29.8 & 33.3 & 25.7 \\
\hline Contraction ratio/\% & & & & & & & & & & \\
\hline for $2 \mathrm{~s}$ & 14.0 & 10.6 & 13.5 & 9.1 & $1.4(7.3)$ & 9.9 & 11.2 & 13.7 & 12.8 & 15.9 \\
\hline $5 \mathrm{~s}$ & 21.4 & 18.6 & 21.2 & 16.1 & $2.7(14.0)$ & 16.8 & 15.6 & 20.4 & 19.5 & 21.4 \\
\hline $10 \mathrm{~s}$ & 25.0 & 23.6 & 25.2 & 19.8 & $3.8(18.6)$ & 21.2 & 17.9 & 23.3 & 23.0 & 23.3 \\
\hline $100 \mathrm{~s}$ & 27.0 & 28.8 & 28.4 & 23.7 & $6.0(22.8)$ & 24.6 & 20.8 & 26.9 & 26.7 & 25.6 \\
\hline Peak response rate $/ \% \mathrm{~s}^{-1}$ & & & & & & & & & & 13.5 \\
\hline
\end{tabular}

Contraction shown above was the third contraction except in the parentheses (the fourth contraction).

Table III. Improvements in actuator performance of TFSI-doped PPy prepared from a methyl benzoate solution of TBATFSI by the addition of higher alcohols $\left(1-\mathrm{C}_{n} \mathrm{H}_{2 n+1} \mathrm{OH}\right)$

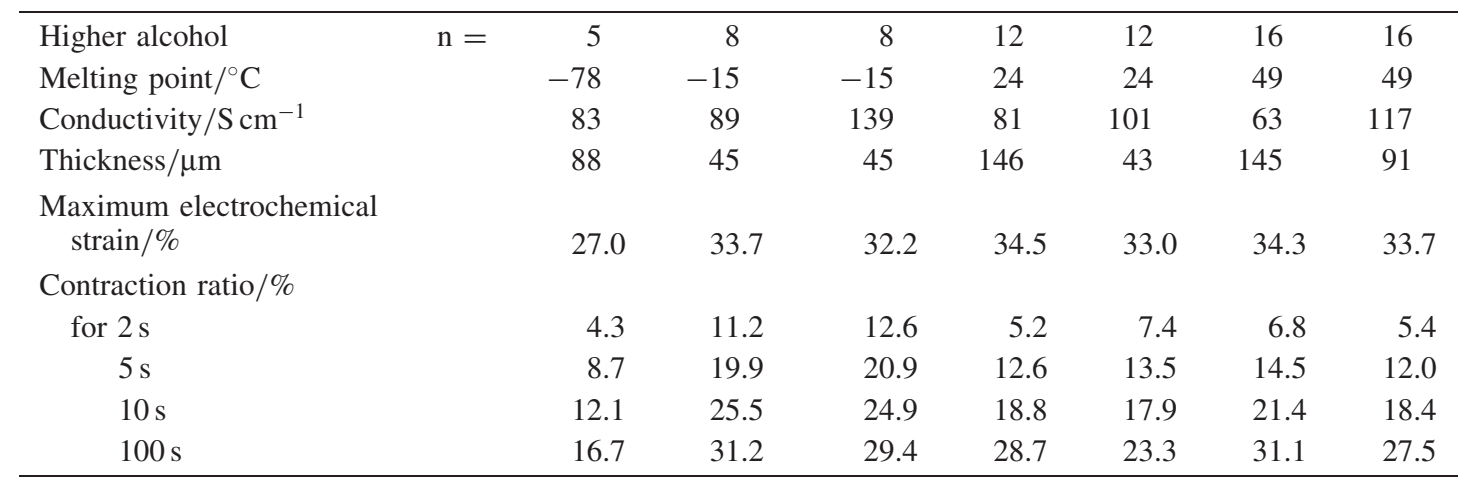

One gram of higher alcohol $\left(1-\mathrm{C}_{\mathrm{n}} \mathrm{H}_{2 \mathrm{n}+1} \mathrm{OH}\right)$ was added to $60 \mathrm{~cm}^{3}$ of methyl benzoate solution of TBATFSI. Electropolymerization was performed on $\mathrm{GC}$ electrode at $+1.4 \mathrm{~V} v \mathrm{~s} . \mathrm{Ag} / \mathrm{AgCl},-10^{\circ} \mathrm{C}$ for $8 \mathrm{~h}$.

MP and MB/MP were almost the same. Electrochemical strains of TFSI-doped PPy actuators prepared on $\mathrm{Ti}$ and Pt electrodes, however, increased when MB/ MP (1/5) was used instead of MP as solvent for the electropolymerization. Note that the ratio of $\mathrm{MB} /$ MP $(1 / 5)$ was determined by a preliminary experiment. ${ }^{14}$

Propylene carbonate (PC), which is a common organic solvent for electrochemistry, decreased the viscosity of electrolytic solution and increased considerably the ionic conductivity, but a PC/MP mixed solution of TBATFSI gave brittle PPy films showing poor actuator performance, and therefore PC is not a suitable solvent for the preparation of PPy with TBATFSI. Similarly, PC was not the best solvent for the preparation of triflate-doped PPy actuators with $\mathrm{TBACF}_{3} \mathrm{SO}_{3}$ as well. ${ }^{15}$

\section{Improvement in Actuator Performance of TFSI-doped} PPy Actuators by the Addition of Higher Alcohol

Table III indicates electrochemical strains and physical properties of TFSI-doped PPy actuators prepared electrochemically from an $\mathrm{MB}$ solution of TBATFSI with higher alcohols $\left(1-\mathrm{C}_{\mathrm{n}} \mathrm{H}_{2 \mathrm{n}+1} \mathrm{OH}\right)$ $(\mathrm{n}=5,8,12$, and 16). The maximum electrochemical strain of TFSI-doped PPy actuators were 33-34\% except one prepared with 1-pentanol. The addition of higher alcohol in the electrolytic solution for the electropolymerization might influence the PPy conformation where PPy chains had space to elongate and shrink effectively even though MB was used as solvent. Note that 1-octanol solution of $\mathrm{TBACF}_{3} \mathrm{SO}_{3}$ gave triflate-doped PPy actuators exhibiting large electrochemical strain and stress as same as MB solution did, and that TBATFSI did not dissolve in 1-octanol. Isomers of 1-octanol such as 2-octanol, 3-octanol, and 2,5-dimethyl-2-hexanol gave similar TFSIdoped PPy actuators as shown in Table IV, and therefore 1-octanol was mainly used as an additive for the electrolytic solution.

Table V indicates electrochemical strains, stresses, and properties of TFSI-doped PPy actuators prepared electrochemically from an MB.MP (1/5) solution of TBATFSI by the addition of 1-octanol. The maximum 
Table IV. Improvements in actuator performance of TFSI-doped PPy prepared from a methyl benzoate solution of TBATFSI by the addition of higher alcohols $\left(\mathrm{C}_{8} \mathrm{H}_{17} \mathrm{OH}\right)$

\begin{tabular}{lcccc}
\hline Higher alcohol & 1-Octanol & 2-Octanol & 3-Octanol & 2,5-Dimethyl-2-hexanol \\
Polymerization time/h & 8 & 9 & 9 & 4 \\
Conductivity $/ \mathrm{S} \mathrm{cm}^{-1}$ & 89 & 67 & 44 & 81 \\
Thickness $/ \mu \mathrm{m}$ & 45 & 153 & 199 & 143 \\
$\begin{array}{l}\text { Maximum electrochemical } \\
\quad \text { strain/\% }\end{array}$ & 33.7 & 33.0 & 29.2 & 32.2 \\
Contraction ratio/\% & & & & \\
$\quad$ for $2 \mathrm{~s}$ & 11.2 & 7.7 & 6.7 & 7.0 \\
$\quad 5 \mathrm{~s}$ & 19.9 & 15.3 & 13.8 & 21.0 \\
$\quad 10 \mathrm{~s}$ & 25.5 & 20.6 & 19.2 & 28.1 \\
\hline $100 \mathrm{~s}$ & 31.2 & 27.0 & 25.3 & \\
\hline
\end{tabular}

One gram of higher alcohol was added to $60 \mathrm{~cm}^{3}$ of the electrolytic solution. Electropolymerization was performed on $\mathrm{GC}$ electrode at $+1.4 \mathrm{~V}$ vs. $\mathrm{Ag} / \mathrm{AgCl},-10^{\circ} \mathrm{C}$.

Table V. Improvements in actuator performance of TFSI-doped PPy prepared from an MB/MP (1/5) solution of TBATFSI by the addition of 1-octanol

\begin{tabular}{|c|c|c|c|c|c|c|}
\hline Addition of 1-octanol/g & 1 & 1 & 4 & 4 & 4 & 4 \\
\hline Electrode & $\mathrm{GC}$ & GC & GC & GC & $\mathrm{Pt}$ & $\mathrm{Pt}$ \\
\hline Potential/V vs. $\mathrm{Ag} / \mathrm{AgCl}$ & +1.6 & +2.0 & +1.4 & +2.0 & +1.4 & +2.0 \\
\hline Polymerization time/h & 8 & 4 & 24 & 24 & 24 & 6 \\
\hline Conductivity $/ \mathrm{S} \mathrm{cm}^{-1}$ & 189 & 84 & 76 & 111 & - & 112 \\
\hline Thickness/ $\mu \mathrm{m}$ & 80 & 102 & 64 & 104 & 94 & 52 \\
\hline $\begin{array}{l}\text { Maximum electrochemical } \\
\text { strain/\% }\end{array}$ & 30.5 & 35.2 & 32.7 & 31.5 & 34.2 & 35.2 \\
\hline Contraction ratio/\% & & & & & & \\
\hline for $2 \mathrm{~s}$ & 0.83 & 12.0 & 1.9 & 1.2 & 14.1 & 15.6 \\
\hline $5 \mathrm{~s}$ & 2.0 & 19.9 & 3.4 & 2.3 & 24.0 & 22.7 \\
\hline $10 \mathrm{~s}$ & 3.1 & 23.8 & 5.0 & 3.3 & 29.3 & 25.7 \\
\hline $100 \mathrm{~s}$ & 6.3 & 27.6 & 10.2 & 5.7 & 34.4 & 30.1 \\
\hline $\begin{array}{l}\text { Maximum electrochemical } \\
\text { stress/MPa }\end{array}$ & & & 3.5 & & 2.6 & \\
\hline Tensile strength/MPa & & & 22.0 & & 12.5 & \\
\hline Elongation/\% & & & 44 & & 21 & \\
\hline
\end{tabular}

1-Octanol was added to $60 \mathrm{~cm}^{3}$ of the electrolytic solution.

electrochemical strains were around $34 \%$, and the largest strain was $35.2 \%$. As the maximum electrochemical strains of TFSI-doped PPy actuators prepared from an MB/MP (1/5) solution of TBATFSI without the addition of 1-octanol shown in Table II were almost equivalent to those indicated in Table $\mathrm{V}$, the influence of 1-octanol was very small, probably because PPy films prepared from MP were soft and less dense such that 1-octanol was not necessary to give TFSI-doped PPy actuators capable of stretching smoothly.

\section{TFSI-doped PPy Films Prepared with Various TFSI} Salts and Their Actuator Performance

Table VI and VII show electrochemical strains and physical properties of TFSI-doped PPy films prepared from a methyl benzoate and an MB/MP (1/5) solutions, respectively, of various TFSI salts such as
EMI-TFSI, EMP-TFSI, BP-TFSI, TMPA-TFSI, and TBATFSI. As TFSI-doped PPy actuators are aniondriven ones, the actuator performance was almost independent of cation used for the electropolymerization. The electrolytic solutions comprising EMI, EMP, BP, and TMPA appeared to be more stable than that comprising TBA, so that TFSI-doped PPy films obtained with EMI-TFSI, EMP-TFSI, BP-TFSI, and TMPA-TFSI might exhibit better durability. The surface morphology of the TFSI-doped PPy films obtained was different from sample to sample, as shown in Figure 1, and the actuator performance such as the maximum electrochemical strain and the response rate should be affected, but the cation effect was not seen as such.

\section{ECMD of TFSI-doped PPy Tube Actuators}

TFSI-doped PPy tubes were easily obtained electro- 
Table VI. Electrochemical strains of TFSI-doped PPy actuators prepared electrochemically from a methyl benzoate solution of various TFSI salts at $+1.2 \mathrm{~V} v$ s. $\mathrm{Ag} / \mathrm{AgCl}$ at $-10^{\circ} \mathrm{C}$

\begin{tabular}{lcccccccccc}
\hline \multicolumn{1}{c}{ Cation } & \multicolumn{2}{c}{ EMI } & \multicolumn{2}{c}{ EMP } & \multicolumn{2}{c}{ BP } & \multicolumn{2}{c}{ TMPA } & TBA \\
\hline Electrode & Pt & GC & Pt & GC & Pt & GC & Pt & GC & Pt & GC \\
Polymerization time $/ \mathrm{h}$ & 8 & 10 & 8 & 10 & 4 & 24 & 7 & 8 & 4 & 8 \\
Conductivity $/ \mathrm{S} \mathrm{cm}^{-1}$ & 65 & 45 & 102 & 122 & 51 & 167 & 50 & 143 & 31 & 21 \\
Thickness $/ \mu \mathrm{m}$ & 44 & 125 & 30 & 21 & 44 & 26 & 45 & 26 & 41 & 66 \\
Maximum strain/\% & 23.4 & 29.0 & 21.6 & 18.2 & 23.6 & 18.3 & 18.7 & 28.2 & 22.6 & 24.9 \\
Contraction ratio/\% & & & & & & & & & & \\
$\quad$ for 2s & 11.5 & 11.8 & 13.2 & 8.8 & 10.4 & 9.8 & 10.1 & 11.4 & 10.2 & 11.5 \\
$\quad 5 \mathrm{~s}$ & 16.9 & 19.5 & 17.8 & 13.0 & 15.5 & 15.0 & 14.5 & 17.9 & 16.1 & 18.5 \\
$10 \mathrm{~s}$ & 19.2 & 23.1 & 19.9 & 15.0 & 15.8 & 17.4 & 16.9 & 21.3 & 19.0 & 21.9 \\
$100 \mathrm{~s}$ & 23.3 & 26.9 & 24.2 & 17.7 & 19.3 & 20.7 & 20.7 & 25.8 & 23.9 & 26.4 \\
\hline
\end{tabular}

Table VII. Electrochemical strains of TFSI-doped PPy actuators prepared electrochemically from an $\mathrm{MB} / \mathrm{MP}(1 / 5)$ mixed solution of various TFSI salts at $+1.4 \mathrm{~V} v s . \mathrm{Ag} / \mathrm{AgCl}$ at $-10^{\circ} \mathrm{C}$

\begin{tabular}{|c|c|c|c|c|c|c|c|c|c|c|c|c|}
\hline \multirow{2}{*}{$\begin{array}{l}\text { Cation } \\
\text { Electrode }\end{array}$} & \multicolumn{2}{|c|}{ EMI } & \multicolumn{2}{|c|}{ EMP } & \multirow[b]{2}{*}{$\mathrm{Au}$} & \multirow[b]{2}{*}{$\mathrm{Ti}$} & \multirow[b]{2}{*}{$\mathrm{Ni}$} & \multirow[b]{2}{*}{ ITO } & \multicolumn{2}{|c|}{$\mathrm{BP}$} & \multicolumn{2}{|c|}{ TMPA } \\
\hline & $\mathrm{Pt}$ & GC & $\mathrm{Pt}$ & GC & & & & & $\mathrm{Pt}$ & GC & $\mathrm{Pt}$ & GC \\
\hline Polym. time/h & 10 & 30 & 24 & 26 & 22 & 22 & 22 & 32 & 27 & 27 & 24 & 28 \\
\hline Conductivity $/ \mathrm{S} \mathrm{cm}^{-1}$ & 83 & 194 & 106 & 120 & 115 & 275 & 142 & 46 & 230 & 249 & 98 & 239 \\
\hline Thickness/ $\mu \mathrm{m}$ & 35 & 51 & 34 & 40 & 57 & 25 & 38 & 49 & 20 & 22 & 39 & 43 \\
\hline Maximum strain $/ \%$ & 26.5 & 33.8 & 24.0 & 28.3 & 28.2 & 23.4 & 25.7 & 9.5 & 25.6 & 34.5 & 28.4 & 30.6 \\
\hline \multicolumn{13}{|l|}{ Contraction ratio/\% } \\
\hline for $2 \mathrm{~s}$ & 12.5 & 8.5 & 10.7 & 14.5 & 11.7 & 10.5 & 12.2 & 5.8 & 13.6 & 12.2 & 12.9 & 11.5 \\
\hline $5 \mathrm{~s}$ & 19.0 & 14.5 & 14.9 & 21.2 & 18.2 & 15.8 & 19.1 & 8.4 & 19.9 & 17.1 & 19.1 & 18.6 \\
\hline $10 \mathrm{~s}$ & 21.8 & 19.2 & 16.8 & 24.3 & 21.7 & 19.2 & 22.2 & 9.4 & 23.0 & 19.6 & 21.9 & 22.4 \\
\hline $100 \mathrm{~s}$ & 26.2 & 25.1 & 21.5 & 28.6 & 24.0 & 22.1 & 25.5 & 9.8 & 27.5 & 22.4 & 27.3 & 26.0 \\
\hline
\end{tabular}

chemically by using a $\mathrm{Pt}$ or $\mathrm{Ni}$ wire as the working electrode. PPy swelled enough to pull the metal wire out when the TFSI-doped PPy on a metal wire was immersed in acetone after the electropolymerization. Figure 2 shows SEM photographs prepared from an MP solution of TFSI on Pt wire as the working electrode. The morphology of the outside and inside of the tube were identical to that of the solution side and the electrode side, respectively, of a TFSI-doped PPy film prepared similarly on Pt plate electrode.

Table VIII indicates ECMD of TFSI-doped PPy tubes driven in a PC/water (40/60) solution of LiTFSI. The maximum electrochemical strain and the contraction ratios of TFSI-doped PPy tubes depended on the solvent used for the electropolymerization. Dimethyl phthalate (MP) solution tended to give softer PPy such that the relatively thick PPy tube prepared from MP might be able to stretch more smoothly than the PPy tube prepared from MB. Similarly, triflate-doped PPy films prepared from MP exhibited slightly larger electrochemical strain. Due to ionic conductivity in the electrolytic solution for the electropolymerization, the polymerization time for MP solution took longer than that for MB solution.
Actuator performance of TFSI-doped PPy tubes prepared on $\mathrm{Ni}$ wire was inferior to that prepared on Pt wire, in analogy with TFSI-doped films prepared on metal plate electrodes. Ni wire electrodes were, however, normally used for the preparation of TFSIdoped PPy tubes as a counter electrode (CE) of PPy$\mathrm{Au}$ coil composite actuator described later. TFSIdoped PPy tube as the CE should be electroactive, but not necessarily stretchable. Moreover, dimensions of CE should be constant rather than changeable.

\section{ECMD of TFSI-doped PPy-Pt/Ir Coil Composite Actuators}

Table IX indicates the frequency dependence on the electrochemical strain of TFSI-doped PPy-Pt/Ir coil composite actuator prepared electrochemically from an MB solution of TFSI. As increased the frequency to drive the PPy-coil composite actuator, the electrochemical strain decreased as same as the other $\mathrm{CP}$ actuators. The metal coil should contribute to decrease voltage drop along the actuator to increase the response rate of the actuator. The peak response rate of a PPy-Pt/Ir coil composite actuator was $6.6 \% \mathrm{~s}^{-1}$, smaller than that $\left(13.8 \% \mathrm{~s}^{-1}\right)$ of a free-standing 


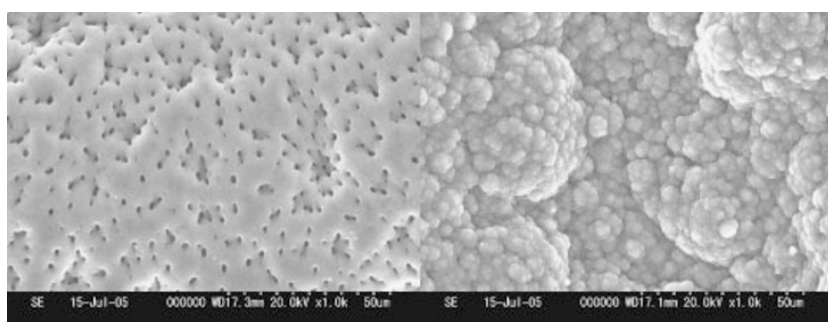

(a)

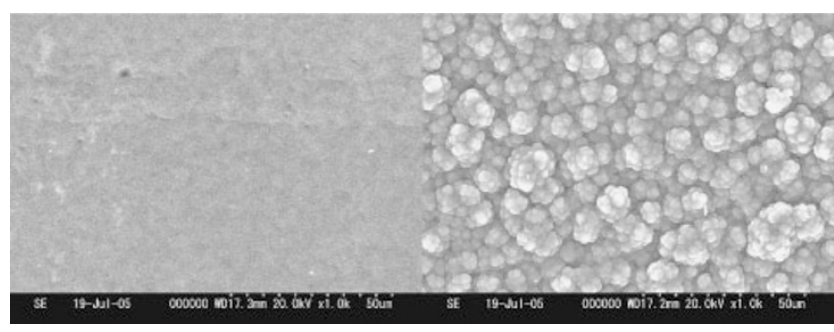

(b)

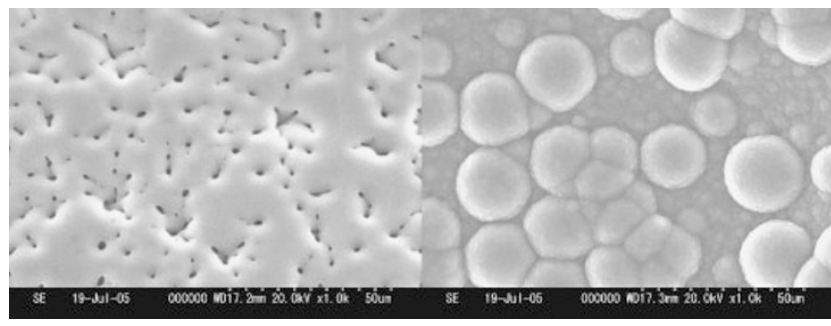

(c)

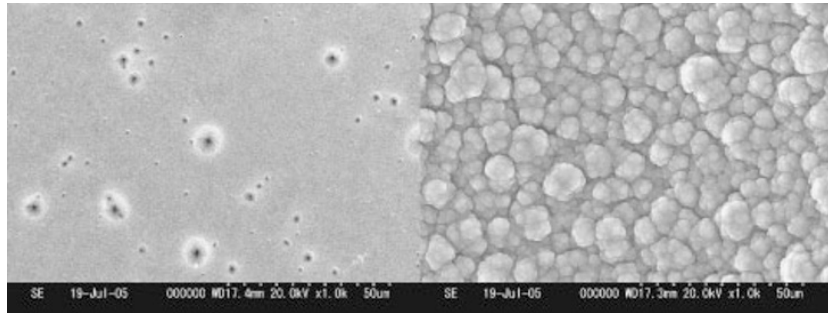

(d)

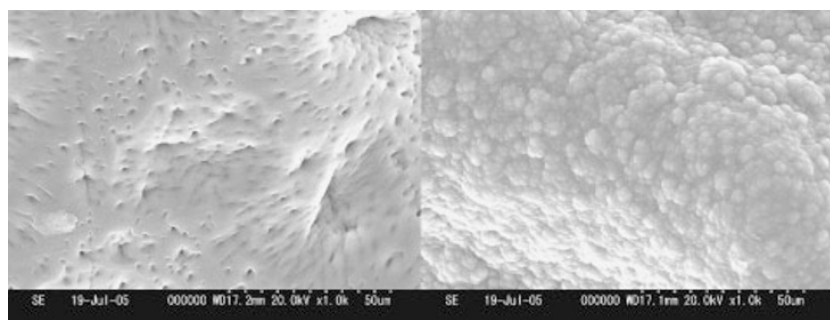

(e)

Figure 1. SEM photographs of TFSI-doped PPy films prepared electrochemically from a methyl benzoate solution of EMI-TFSI (a), EMP-TFSI (b), BP-TFSI (c), TMPA-TFSI (d), and TBA-TFSI (e), shown in Table VI. Electrode side (left) and solution side (right).

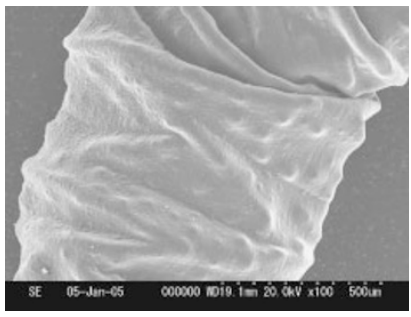

(a)

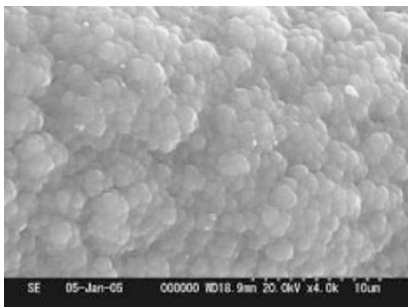

(c)

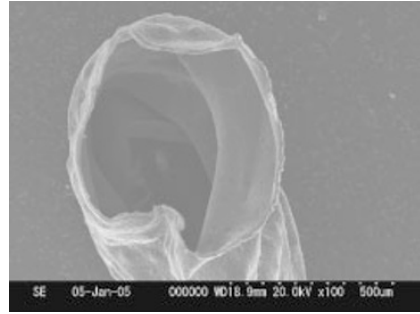

(b)

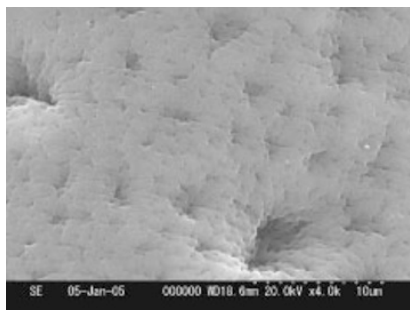

(d)
Figure 2. SEM photographs of a TFSI-doped PPy tube prepared electrochemically from an MP solution of TBATFSI on Pt wire $(0.8 \mathrm{~mm} \phi)$ at $+1.4 \mathrm{~V}$ vs. $\mathrm{Ag} / \mathrm{AgCl}$; a: outside of the tube, $\mathrm{b}$ : one end of the tube, c: surface of the outside of the tube (solution side), d: surface of the inside of the tube (electrode side).
TFSI-doped PPy film. ${ }^{18}$ This result suggests that the metal coil disturbed ECMD of PPy-coil composite actuators. Practically, however, TFSI-doped PPy film actuators are not mechanically strong as triflate-doped PPy film actuators, and thus TFSI-doped PPy should be supported by compliant metal electrodes such as metal coils. TFSI-doped PPy-metal coil composite actuators can pull and push without complicated mechanisms because CPs expand and shrink three-dimensionally with doping and dedoping, respectively, whereas PPy film actuators need some mechanisms to push; otherwise the film actuators would be bent or curved.

\section{TFSI-doped PPy-Au Coil Composite Actuator for} Small Actuator Devices

Figure 3 shows a photograph and a schematic diagram of a small device comprising a TFSI-doped PPy-Au coil composite actuator, whose length and effective length (a stretchable part of PPy-Au coil actuator) were $32 \mathrm{~mm}$ and $27 \mathrm{~mm}$, respectively. A TFSIdoped PPy tube prepared on Ni wire $(0.8 \mathrm{~mm} \phi)$ was used as the CE. The PPy-Au coil composite actuator and the PPy tube were separated by a porous poly- 
Table VIII. Electrochemical strains of tubular TFSI-doped PPy actuators prepared electrochemically with TBATFSI at $-10^{\circ} \mathrm{C}$

\begin{tabular}{lcccc}
\hline Electrode (wire) & $\mathrm{Pt}$ & $\mathrm{Pt}$ & $\mathrm{Pt}$ & $\mathrm{Ni}$ \\
Solvent & $\mathrm{MB}$ & $\mathrm{MB} / \mathrm{MP}(1 / 5)$ & $\mathrm{MP}$ & $\mathrm{MP}$ \\
Potential/V vs. $\mathrm{Ag} / \mathrm{AgCl}$ & +1.4 & +1.4 & +1.4 & +1.4 \\
Polymerization time/h & 2 & 4.7 & 6 & 8 \\
$\quad \begin{array}{l}\text { Maximum electrochemical } \\
\quad \text { strain/\% }\end{array}$ & 24.8 & 32.8 & 37.4 & 20.2 \\
Contraction ratio/\% & & & & \\
$\quad$ for $2 \mathrm{~s}$ & 4.7 & 6.4 & 11.8 & 9.2 \\
$\quad 5 \mathrm{~s}$ & 10.1 & 12.7 & 20.8 & 14.3 \\
$\quad 10 \mathrm{~s}$ & 14.4 & 16.7 & 27.3 & 16.8 \\
$\quad 100 \mathrm{~s}$ & 20.6 & 22.8 & 37.7 & 20.8 \\
Peak response rate $/ \% \mathrm{~s}^{-1}$ & & & 8.6 & 5.4 \\
\hline
\end{tabular}

Diameter of the wires; Pt: $0.8 \mathrm{~mm}, \mathrm{Ni}: 1.0 \mathrm{~mm}$.

Table IX. Repeated ECMD of TFSI-doped PPy-Pt/Ir coil composite actuators driven at $\pm 0.7 \mathrm{~V} v s$. $\mathrm{Ag} / \mathrm{Ag}^{+}$in $\mathrm{PC} /$ water $(40 / 60)$ solution of LiTFSI at various frequencies

\begin{tabular}{cc}
\hline Frequency $/ \mathrm{Hz}$ & Electrochemical strain $/ \%$ \\
\hline 0.1 & 7.9 \\
0.05 & 12 \\
$0.000625^{\mathrm{a}}$ & 20.8 \\
\hline
\end{tabular}

${ }^{\mathrm{a} C y c l e d}$ between $-0.9 \mathrm{~V}$ and $+0.7 \mathrm{~V}$ vs. $\mathrm{Ag} / \mathrm{Ag}^{+}$at $2 \mathrm{mV} \mathrm{s}^{-1}$.
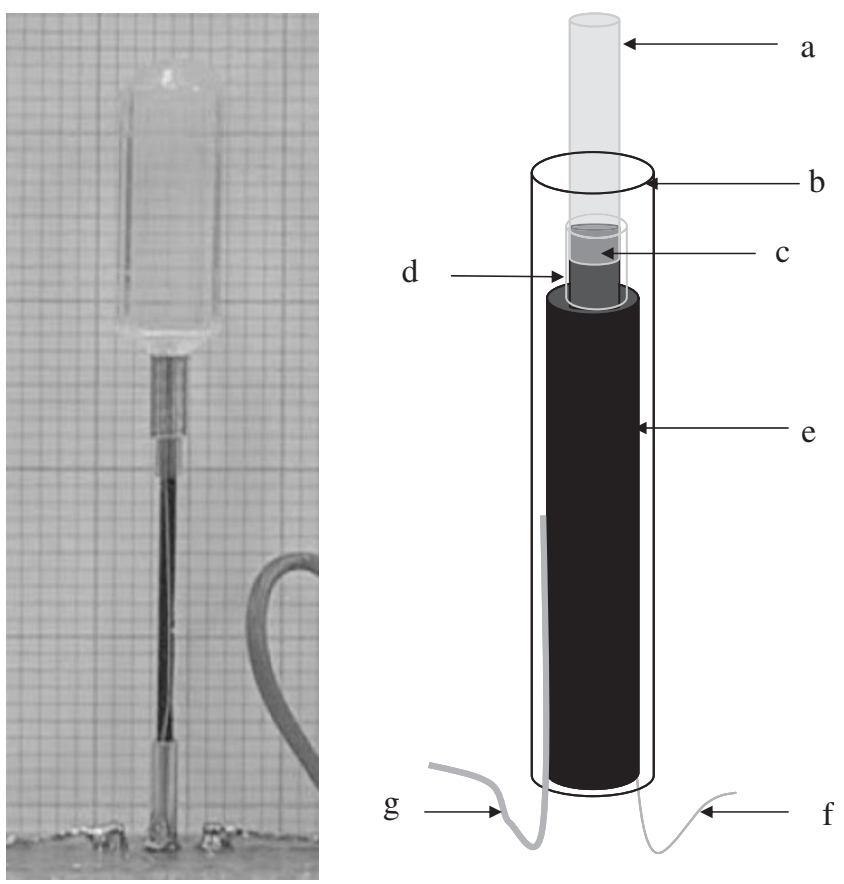

Figure 3. A photograph and a schematic diagram of a TFSIdoped PPy-Au coil composite actuator; a: polyimide tube, b: glass tube $(\phi 0.9 \mathrm{~mm}), \mathrm{c}$ : TFSI-doped PPy-Au coil actuator, d: separator, e: TFSI-doped PPy tube as the counter electrode (CE), f: Au lead wire for PPy-Au coil actuator, g: Au lead wire for CE. Length of the actuator: $32 \mathrm{~mm}$, effective length: $27 \mathrm{~mm}$, load: $0.5 \mathrm{~g}$.

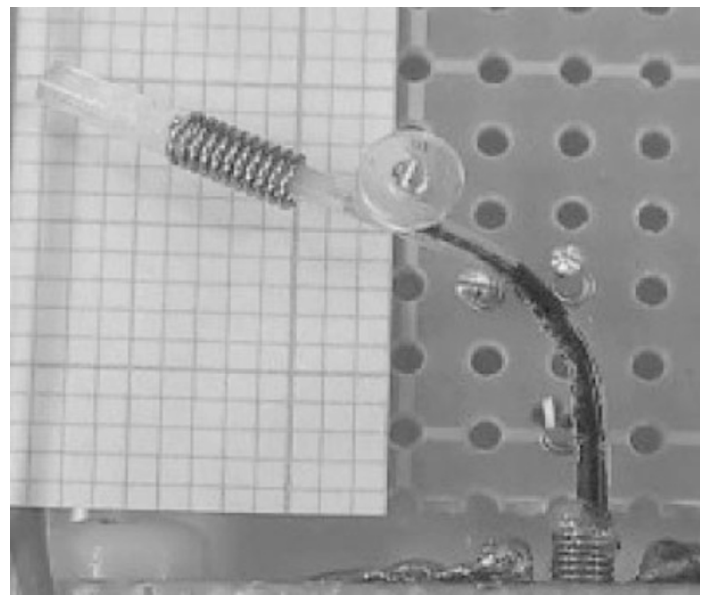

Figure 4. A photograph of a bent TFSI-doped PPy-Au coil composite actuator whose diameter (tube), length, and bent angle are $1.1 \mathrm{~mm}, 15 \mathrm{~mm}$, and $60^{\circ}$, respectively.

(vinylalcohol) (PVA) thin film prepared by an electrospinning method. A glass capillary tube $(0.9 \mathrm{~mm} \phi)$ was used as the cover, in which a PC/water solution of LiTFSI was filled as the electrolyte, when the PVA film became a gel-like separator. One end of the PPyAu coil was connected with a polyimide tube in order to take force generated by the actuator out of the cell. Top of the actuator shown in the photo was a load $(0.5$ g). This actuator device was able to stretch smoothly at $0.2-0.5 \mathrm{~Hz}$ by applying $\pm 0.7 \mathrm{~V} v s . \mathrm{Ag} / \mathrm{Ag}^{+}$.

Figure 4 shows a photograph of a small device whose length and load were $15 \mathrm{~mm}$ and $0.2 \mathrm{~g}$, respectively. The device was able to be bent by using a fluoropolymer tube $(1.1 \mathrm{~mm} \phi)$ as the cover instead of the glass capillary. The bent angle of $60^{\circ}$ was achieved without showing any disturbance of ECMD at 0.2$0.5 \mathrm{~Hz}$ by applying $\pm 0.7 \mathrm{~V} v s$. $\mathrm{Ag} / \mathrm{Ag}^{+}$.

These small devices (artificial muscle fibres) were most suitable for pushing, so a tactile display and micro-valves should be promising applications. When 
more force is required, some TFSI-doped PPy-metal coil composites could be bundled to adjust force generated electrochemically. ${ }^{19}$ Practically, however, TFSI-doped PPy actuators are most useful for small devices, whereas relatively large devices should be fabricated with triflate-doped zigzag metal wire composite actuators. ${ }^{20}$

\section{CONCLUSION}

TFSI-doped PPy film actuators, prepared electrochemically from an $\mathrm{MB} / \mathrm{MP}(1 / 5)$ solution of TBATFSI, exhibited up to $35 \%$ maximum electrochemical strain almost equivalent to those (20-40\%) of mammal skeltal muscles, and the maximum response rate up to $13.8 \% \mathrm{~s}^{-1}$ should make it possible to apply to artificial muscle devices. TFSI-doped PPy metal coil composite actuators were versatile small devices capable of pushing and pulling without complicated mechanisms. TFSI-doped PPy with moderate mechanical strength should be supported with compliant electrodes such as the metal coil.

\section{REFERENCES}

1. J. D. Madden, A. Vandesteeg, P. A. Anquetil, P. G. Madden, A. Takshi, R. Z. Pytel, S. Lafontaine, P. A. Wieringa, and I. W. Hunter, IEEE J. Oceanic Eng., 29, 706 (2004).

2. R. H. Baughman, L. W. Shacklette, R. L. Elsenbaumer, E. J. Plichta, and C. Becht, "Topics in Molecular Organization and Engineering: Molecular Electronics," Vol. 7, P. I. Lazarev, Ed., Kluwer, Dordrecht, 1991, p. 267.
3. R. H. Baughman, Synth. Met., 78, 339 (1996).

4. A. Della Santa, D. De Rossi, and A. Mazzoldi, Synth. Met., 84, 93 (1997).

5. T. F. Otero and J. M. Sansinena, Adv. Mater., 10, 491 (1998).

6. I. W. Hunter and S. Lafontaine, Tech. Digest, IEEE Solid State Sensor Actuator Workshop, 1992, p. 178.

7. R. H. Baughman, Science, 308, 63 (2005).

8. S. Hara, T. Zama, W. Takashima, and K. Kaneto, J. Mater. Chem., 14, 1516 (2004).

9. W. Takashima, M. Kaneko, K. Kaneto, and A. G. MacDiarmid, Synth. Met., 71, 2265 (1995).

10. http://www.eamex.co.jp/denshi_hp/movies/bimorph_inAir_ edit.wmv

11. M. Ue, J. Electrochem. Soc., 141, 3336 (1994).

12. S. Hara, T. Zama, W. Takashima, and K. Kaneto, Polym. J., 36, 933 (2004).

13. S. Hara, T. Zama, W. Takashima, and K. Kaneto, Synth. Met., 149, 199 (2005).

14. S. Hara, T. Zama, W. Takashima, and K. Kaneto, Smart Mater. Struct., 14, 1501 (2005).

15. S. Hara, T. Zama, W. Takashima, and K. Kaneto, Polym. J., 36, 151 (2004).

16. T. Zama, S. Hara, W. Takashima, and K. Kaneto, Bull. Chem. Soc. Jpn., 77, 1425 (2004).

17. T. Zama, S. Hara, W. Takashima, and K. Kaneto, Bull. Chem. Soc. Jpn., 78, 506 (2005).

18. S. Hara, T. Zama, N. Tanaka, W. Takashima, and K. Kaneto, Chem. Lett., 34, 784 (2005).

19. S. Hara, T. Zama, W. Takashima, and K. Kaneto, Synth. Met., 146, 47 (2004).

20. S. Hara, T. Zama, W. Takashima, and K. Kaneto, J. Mater. Chem., 14, 2724 (2004). 